\title{
High-Status Exemplars and the Misperception of the Asian-White Wealth Gap
}

\author{
Enya Entung Kuo ${ }^{1,2}$, Michael W. Kraus ${ }^{2}$, Jennifer A. Richeson ${ }^{3,4}$ \\ ${ }^{1}$ University of California, Los Angeles \\ ${ }^{2}$ Yale University, School of Management \\ ${ }^{3}$ Yale University, Department of Psychology \\ ${ }^{4}$ Yale University, Institution for Social and Policy Studies
}

Final Word Count: 5000

Enya Entung Kuo graduated from UCLA in the Class of 2019. She is broadly interested in intergroup relations, coalition building, and political psychology.

Michael W. Kraus is an assistant professor at the Yale University School of Management. He specializes in the study of inequality, and his current work explores the behaviors and emotional states that maintain and perpetuate economic and social inequality in society.

Jennifer A. Richeson is the Philip R. Allen Professor of Psychology at Yale University. She studies multiple psychological phenomena related to cultural diversity, and her current research is largely focused on dynamics and consequences of increasing racial, ethnic, and other forms of cultural diversity, most notably the rising racial/ethnic diversity of the nation. 


\begin{abstract}
In this research, we test the central hypothesis that perceptions of Asian Americans as a highstatus "model minority" lead to overestimates of the extent of wealth equality between Asian and White Americans. We test this hypothesis across three studies that manipulate the salience of high- or low-status Asian American exemplars before soliciting estimates of Asian-White wealth equality. A meta-analysis of the results revealed that participants significantly overestimated Asian-White wealth equality, and that making low- versus high-status Asian American exemplars salient decreased this tendency. These data suggest that activation of high-status Asian American exemplars elicits greater overestimates of Asian-White wealth equality, obscuring existing wealth disparities relative to White Americans and significantly downplaying the economic inequality that burdens a subset of Asian Americans from less-prototypical ethnic backgrounds. The findings echo recent calls by sociologists and political scientists for a more nuanced understanding of the diversity and economic inequality among Asian American communities.
\end{abstract}

Keywords: economic inequality; social cognition; race relations; diversity; policymaking 


\section{High-Status Exemplars and the Misperception of the Asian-White Wealth Gap}

Asian Americans are commonly perceived in the United States as a monolithic racial group (e.g., Ong, Burrow, Fuller-Rowell, Ja, \& Sue, 2013; Sue, Bucceri, Lin, Nadal, \& Torino, 2007) despite members of this broad category having roots in more than twenty countries with unique cultures and immigration histories (Lee \& Zhou, 2015; López, Ruiz, \& Patten, 2017). Perceptions of Asian immigrants tend to focus on the more recent arrivals during the last few decades after 1965 , often overlooking waves of immigration that began as early as the $19^{\text {th }}$ century (Spickard, 1999). This tendency results in perceptions of Asian Americans in aggregate as high in socio-economic status both in general and relative to other racial minority groups, owing in some measure to the high proportion of hyper-selected Asian immigrants (i.e., highlyeducated immigrants from China and India) among this latter wave (Lee \& Zhou, 2015). It is also owing to these high-status prototypical Asian subgroups that people are largely unaware of the within-group economic inequality among Asian Americans (Fiske, Cuddy, Glick, \& Xu, 2002; Ong et al., 2013; Sue et al., 2007; Zou \& Cheryan, 2017), some of whom come to America as refugees escaping conflict and live in food and financial insecurity (Kochhar \& Cillufo, 2018).

In this research, we predict and test the central hypothesis that the tendency to think of Asian Americans as a high-status group results in the tendency to overestimate wealth equality between Asian and White Americans. We test this general hypothesis across three studies that manipulate the salience of high- or low-status Asian American exemplars. One direct implication of this work is that activation of the prototypical image of Asian Americans directly impacts how Americans, as a whole, downplay or outright ignore the significant economic inequalities that burden a subset of Asian American families.

Two lines of research provide rationale for our central prediction. First, a growing body of research indicates that people are overly optimistic about levels of economic equality in 
general (Kiatpongsan \& Norton, 2014; Norton \& Ariely, 2011) and between Black and White Americans (Kraus, Rucker, \& Richeson, 2017). In that latter research, samples of Black and White Americans overestimated current levels of equality in healthcare, wealth, income, and wages shared between Black and White Americans by more than 20 percentage points on average (Kraus et al., 2017). These studies align with prior work indicating that people believe that Americans have made substantial progress toward racial equality in society (Eibach \& Ehrlinger, 2006; Wilkins, Hirsch, Kaiser, \& Inkles, 2017), perceptions inconsistent with actual indices of wealth inequality, for instance, which suggest that Black Americans had roughly $\$ 10$ for every $\$ 100$ held by Whites since the 1960s (Hamilton, Darity, Price, Sridharan, \& Tippett, 2015). In the particular case of perceptions of Asian-White wealth equality, in addition to narratives of racial progress, Asian American exemplars tend to be high in social status. Perceptions of Asian Americans are thus likely to reflect this advantaged subset of the racial category, thereby eliciting overestimates of Asian-White wealth equality. In this research, we directly test the prediction that Americans will overestimate Asian-White wealth equality in a similar — though less extreme-fashion.

Second, prototypical racial group representations and exemplars are likely to play a significant role in eliciting overestimates of Asian-White wealth equality (Brown-Iannuzzi, Dotsch, Cooley, \& Payne, 2017; Lei \& Bodenhausen, 2017). As we argued, Asian Americans are largely perceived to be high in social status in general and relative to other racial minority groups like Latinx and Black Americans (Zou \& Cheryan, 2017). Additionally, according to data from the General Social Survey, people are aware that Asian Americans, when considered as a broad category, are wealthier than other racial minority groups (Xu \& Lee, 2013) and higher in income relative to Whites (Kochhar \& Cillufo, 2018). Perceptions of the overall category, largely driven by more prototypical subgroups and stereotypical "model minority" exemplars, we argue, are 
likely to lead to overestimates of Asian-White wealth equality. However, making salient lowerstatus exemplars or subgroups should reduce these overestimates.

We tested two specific hypotheses in the present research: (1) Americans will systematically overestimate wealth equality between Asian and White Americans; and (2) overestimation of Asian-White wealth equality is caused, in part, by the salience of high- (versus low-) status Asian American exemplars. To test our two specific hypotheses, we used three methods to activate high- versus low-status exemplars of Asian Americans, through (1) news summaries of Asian American social issues on college campuses, (2) narratives of Asian American immigrants, and (3) aggregating or disaggregating Asian American subgroups that differ in prototyicality prior to estimating wealth disparities. Across studies, we expected that people would overestimate Asian-White wealth equality overall, but that activating low-status exemplars would reduce these overestimates relative to the activation or salience of high-status exemplars.

\section{Method}

\section{Overview}

We report all measures, manipulations, and exclusions in these studies. In all studies, our main objectives were to measure perceptions of Asian-White wealth equality and manipulate participants' perceived status of Asian Americans, by making salient different exemplars or subgroups of the category, through a) information about college student concerns (Study 1), b) narratives, photographs, and national origins of specific Asian American individuals (Study 2), or c) disaggregating Asian Americans into subgroups that vary in their prototypicality with the larger category (Study 3).

In all studies, an informed consent page explained that the study examined how “perceptions of news media" (Study 1), "personal stories of immigrants" (Study 2), or 
“individual personality" (Study 3) were related to social judgments. Participants were informed that they would fill out surveys assessing their beliefs about society, their responses were anonymous, and they could skip any questions without loss of compensation. After consenting, participants were randomly assigned to one of the experimental conditions (Study 1: low-status, high-status, foreigner; Study 2: low-status, high-status; Study 3: low-status, high-status). Participants were next provided with definitions of wealth and income (Norton \& Ariely, 2011) before responding to critical dependent variables related to wealth equality. Lastly, participants completed measures of related psychological constructs and demographic questions and were debriefed about study hypotheses.

\section{Participants}

For each study, a large online sample of participants was recruited to take a 10- to 15minute survey. Study 1 and 2 participants were recruited through Amazon MTurk; Study 3 participants were recruited through Prolific, another online crowdsourcing platform, out of concern that bot responses contaminated data on MTurk (Bai, 2018). All participants were compensated $\$ 1.50$ for participation, and all consented to participate in this research, approved by the Yale University institutional review board.

In Study 1 ( $n=603 ; 257$ women, $\left.M_{a g e}=35.33, S D_{a g e}=11.83\right)$, the largest ethnoracial group was European American/White $(n=404)$, followed by African American/Black $(n=92)$, Asian American $(n=48)$, Latino/a $(n=36)$, Other $(n=12)$, and American Indian $(n=11)$. The sample size of each study was determined before any data analysis. Our target sample size of 200 per condition guaranteed us greater than $99 \%$ power to detect an $R=0.21$ effect size, the average effect size in the history of social psychology (Richard, Bond, \& Stokes-Zoota, 2003).

In Study 2 ( $n=607 ; 276$ women, $\left.M_{a g e}=36.80, S D_{a g e}=12.85\right)$, the largest ethnoracial group was European American/White $(n=450)$, followed by African American/Black $(n=51)$, Asian 
American $(n=41)$, Latino/a $(n=28)$, Other $(n=19)$, and American Indian $(n=18)$. Because the size of the difference between the low- and high-status conditions was smaller than anticipated in Study 1, we increased our target sample size to 300 per condition to give us $80 \%$ power to detect an $R=0.11$ effect size. We also increased the salience of status in our manipulation in Study 2 to make the experimental manipulation of status more powerful (see below).

In Study 3 ( $n=612 ; 284$ women, $\left.M_{a g e}=32.35, S D_{a g e}=11.26\right)$, the largest ethnoracial group was European American/White $(n=446)$, followed by Asian American $(n=57)$, African American/Black $(n=45)$, Latino/a $(n=32)$, Other $(n=20)$, and American Indian $(n=4)$. Our target sample size remained 300 per condition.

See Table 1 for all participant demographic characteristics. All participants were included in analyses across all studies except in specific cases where they had missing data. The studies reported here represent all of the studies we conducted on this topic. Uniquely, Study 3 was

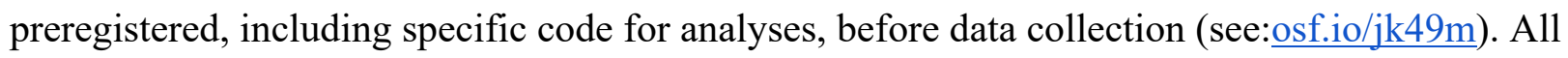
meta-analytic estimates of effect sizes are conducted using fixed effects models (Goh, Hall, \& Rosenthal, 2016).

Table 1. Demographic Characteristics of Participants from Studies 1, 2, and 3

\begin{tabular}{lrrr}
\hline Variable & Study 1 & Study 2 & Study 3 \\
\hline Sample size & 603 & 607 & 612 \\
Age, y, mean (SD) & $35.33(11.83)$ & $36.80(12.85)$ & $32.35(11.26)$ \\
Conservatism, mean (SD) & $3.87(1.83)$ & $3.78(1.74)$ & $3.03(.58)$ \\
High school degree, \% & 27.86 & 29.28 & 36.44 \\
Female, \% & 42.62 & 45.47 & 46.41 \\
Median income & $\$ 40,001-\$ 60,000$ & $\$ 40,001-\$ 60,000$ & $\$ 40,001-\$ 60,000$ \\
White, \% & 67.00 & 74.14 & 72.88 \\
\hline
\end{tabular}




\section{Asian American Status Manipulations}

Study 1. In Study 1, we manipulated the perceived status of Asian Americans by heightening participants' access to different Asian American exemplars (Lee \& Zhou, 2015; Zou \& Cheryan, 2017). Participants were randomly assigned to read a university newspaper's Twitter updates about a low- or high-status group of Asian American students or, instead, a foreign student group (for all study materials, see:osf.io/kcsjf/).

In the low-status condition, participants read that the Asia Refugee Rights Network urged the university to offer more academic and financial resources to low-income and first-generation students. In the high-status condition, participants read that the Society of Asian Scientists and Engineers advocated for more merit-based scholarships to students in science and engineering.

Because recent research indicates that foreignness is a salient stereotype of Asian Americans (Kim, 1999; Xu \& Lee, 2013; Zou \& Cheryan, 2017), we included a third condition highlighting the apparent foreignness of Asian American students. In the foreigner condition, participants read that the Asia International Student Society advocated for more language and community resources to international students. Because college campuses are so intimately tied to "model minority" stereotypes, we expected the foreignness manipulation to reinforce highstatus aspects of Asian Americans as a group.

Study 2. In Study 2, we manipulated the perceived status of Asian Americans more strongly through a combined manipulation of a narrative, photograph of an Asian individual who varied in skin tone (Willer, Feinberg, \& Wetts, 2016), and country of origin (Lee \& Zhou, 2015). Participants were randomly assigned to read the story of a low-status or high-status Asian American immigrant. To increase immersion in the intervention, participants also listened to the narrative via recordings ostensibly by the protagonist.

In the low-status condition, participants saw a photograph of a young woman with dark 
skin and read that this woman, Sophia Meng, is a Cambodian American who immigrated with her family as refugees from Cambodia to escape the civil war. Sophia's mother is a supermarket cashier, and her father is unemployed. She works part-time as a waiter and hopes to find a fulltime job to help with bills. In the high-status condition, Sophia has lighter skin and is Chinese American. Her family immigrated to seek better opportunities. Sophia's mother is a radiologist and her father a software engineer. She plays the piano in her spare time and hopes to become a doctor like her mother. Controlling for foreignness, in both conditions Sophia struggled to learn English and experienced stereotypes of foreignness, such as people not believing that she was from California.

Study 3. In Study 3, we manipulated the perceived status of the Asian American category by asking participants to think about Asian Americans as a general, aggregated pan-ethnic whole or, instead, by first considering ten Asian-origin subgroups based on the groups reported by the 2016 National Asian American Survey (Ramakrishnan, Lee, Lee, \& Wong, 2017). We reasoned that highlighting Asian-origin subgroups would increase the salience of low-status Asian American exemplars and affect the perceived status of the entire category. Asian-origin subgroups have distinct patterns of arrival, either through, for instance, the skilled work H-1B visa like immigrants from India (Kochhar \& Cillufo, 2018), or through refugee settlement as in the case of Vietnam and Cambodia (Zong \& Batalova, 2016). These migration patterns engender different levels of social status as a function of subgroup, which we used in our manipulation for Study 3.

Participants in the low-status condition were asked to first make Asian-White wealth equality estimates for ten Asian-origin subgroups and then make general Asian-White wealth equality estimates for the groups in aggregate. Participants in the high-status condition were asked to make the same estimates in reverse order; thus, aggregate estimates occurred after our 
main dependent measure.

\section{Measures}

Estimates of Asian-White wealth equality. We measured participants' estimates of Asian-White wealth equality using items similar to those used in Kraus et al. (2017). We asked participants to, thinking of current times, estimate the wealth of an average Asian American family "for every $\$ 100$ in wealth accumulated by an average White family." Participants entered their estimates on a $0-200$ scale, in which a zero indicates that Asian families have no wealth, and a 200 indicates that Asian families have double the wealth of White families. We refer to this measure as general Asian-White wealth equality estimates.

We also measured wealth equality estimates at the subgroup level for ten Asian-origin subgroups, based on the six largest subgroups plus South and Southeast Asian subgroups reported by the 2016 National Asian American Survey (Ramakrishnan et al., 2017): Asian Indian, Bangladeshi, Cambodian, Chinese, Filipino, Hmong, Japanese, Korean, Pakistani, and Vietnamese. We presented the subgroups in random order, which did not affect results. We refer to this measure as subgroup-level Asian-White wealth equality estimates.

Subjective social status of Asian Americans. In all three studies, we measured participants' perceptions of the social status of Asian Americans using the MacArthur Scale of Subjective Social Status (Adler, Epel, Castellazzo, \& Ickovics, 2000). An illustration of a tenrung ladder represented ascending levels of income, educational, and occupational status in the United States, and participants placed Asian Americans on one of the rungs. See the online supplement for all descriptive statistics of the psychological correlates.

Familiarity with Asian subgroups. In Studies 1 and 2, participants indicated how familiar they were with each of the ten Asian-origin subgroups (10 items; Study 1: $\alpha=0.93$; Study 2: $\alpha=0.92)$ on a five-point Likert scale (1=not familiar at all, 5=extremely familiar $)$. 
Political ideology. We measured economic and social political orientation (2 items;

Study 1: $\alpha=0.89$; Study 2: $\alpha=0.87$; Study 3: $\alpha=0.84)$ on seven-point Likert scales $(1=$ very liberal, $7=$ very conservative).

Belief in a just world. In Studies 1 and 2, we measured general beliefs in a just world (Lipkus, 1991) with six items (e.g., "I think basically the world is a just place"; Study 1: $\alpha=0.92$; Study 2: $\alpha=0.91)$ on six-point Likert scales (1=strongly disagree, $6=$ strongly agree $)$.

Social dominance orientation. In Study 2, we measured social dominance orientation (Pratto, Sidanius, Stallworth, \& Malle, 1994) with eight items (e.g., "Some groups of people are simply inferior to other groups"; $\alpha=0.89)$ on a seven-point Likert scale (1=strongly oppose, $7=$ strongly favor $)$.

Inclusion of Asian-origin subgroups. Park (2008) found a subtle hierarchy within the label "Asian American" such that East Asian-origin subgroups (e.g., Chinese) come more readily to mind (i.e., are more prototypical) than Southeast (e.g., Vietnamese) and South (e.g., Indian) Asian-origin subgroups. Therefore, in Study 3, after participants made their general Asian-White wealth equality estimates, we presented a list of ten Asian subgroups, plus three South American countries, three African countries, and three European countries. Participants indicated the countries they had in mind when making general Asian-White wealth equality estimates.

\section{Results}

\section{Manipulation Check}

As a manipulation check, participants in Study 1 and 2 completed a recall task at the end of the experiment. In Study 1, 492 participants (81\%) correctly answered the question, "What was the content of the tweets that you read?" Only in Study 1 did participants differentially fail the manipulation check by condition, $F(2,600)=4.80, p=0.009$ (see supplement). In Study 2, participants answered four questions (e.g., "Where is Sophia Meng from?”). Of the sample, 556 
$(92 \%)$ did better than chance at the recall task, meaning they answered at least three questions correctly. Participants' mean scores on the manipulation check questions (out of four) did not differ by condition, $t(605)=1.34, p=0.180$.

We did not plan to remove participants who failed the manipulation check, because removal threatens the validity of the manipulation (Montgomery, Nyhan, \& Torres, 2018). The general pattern of results is roughly the same if participants who did not successfully complete the manipulation check and check for data quality are excluded. For Study 3, all preregistered analyses are reported in the manuscript or supplementary online materials except data quality analyses for our captcha question: Participants who failed the captcha were not invited to complete the rest of the study, so we could not analyze data quality for these participants.

\section{Perceptions of Asian-White Wealth Equality}

To test our first hypothesis, we examined whether our sample of Americans overestimated Asian-White wealth equality. To conduct this analysis, we computed accuracy scores for participants' perceptions of Asian-White wealth equality across studies and experimental conditions by subtracting 84.73 - the median federal estimate of Asian wealth per \$100 in White wealth, calculated from the 2013 Survey of Income and Program Participation (SIPP; "Wealth, Asset Ownership, \& Debt of Households Detailed Tables: 2013," 2013)—from these estimates. Thus, an accuracy score of zero indicates perfect accuracy in the estimate of Asian-White wealth equality, and a positive score indicates an overestimate of equality.

Consistent with our first hypothesis, participants significantly overestimated Asian-White wealth equality in Study $1(M=11.71, C I 95 \%(8.80,14.62), t(602)=7.90, p<0.001, d=0.64)$, Study $2(M=12.44, C I 95 \%(9.76,15.12), t(606)=9.12, p<0.001, d=0.74)$, and Study 3 $(M=13.86, C I 95 \%(11.56,16.16), t(603)=11.85, p<0.001, d=0.97)$. A meta-analysis across studies and experimental conditions (Goh et al., 2016) reveals that participants significantly 
overestimated Asian-White wealth equality, $d_{\text {combined }}=0.78, Z_{\text {Combined }}=16.23, p_{\text {Combined }}<0.001$.

\section{Social Status and Perceptions of Asian-White Wealth Equality}

Our second hypothesis held that manipulating the salience of low- versus high-status Asian American exemplars or subgroups would reduce overestimates of Asian-White wealth equality. We tested this across our three experiments using different manipulations of low- and high-status Asian Americans (see Figure 1).

In Study 1, we heightened the salience of low-status $(n=203)$, high-status $(n=201)$, or foreign ( $n=199)$ Asian Americans exemplars on college campuses. We conducted a one-way between-subjects analysis of variance (ANOVA) to investigate differences between conditions on general Asian-White wealth equality perceptions. The effect of the manipulation on general Asian-White wealth equality estimates was not significant, $F(2,600)=1.43, p=0.239$. A descriptive examination of means reveals that the pattern was, however, aligned with expectations, as participants in the low-status condition made more accurate estimates $(M=8.56)$, CI 95\% $(2.99,14.13)$ than participants in the high-status condition $(M=11.95), C I 95 \%(7.41$, $16.50),(d=0.09)$ and foreigner condition $(M=14.69), C I 95 \%(9.69,19.68),(d=0.16)$.

In Study 2, we used narratives, country of origin, and skin tone to manipulate the low $(n=302)$ and high status $(n=305)$ of Asian American exemplars. Consistent with predictions, an independent samples t-test revealed that participants made significantly more accurate general Asian-White wealth equality estimates in the low-status condition $(M=7.55), C I 95 \%(3.76$, 11.33) than the high-status condition $(M=17.29), C I 95 \%(13.56,21.02), t(605)=3.61, p<0.001$, $d=0.29$. 

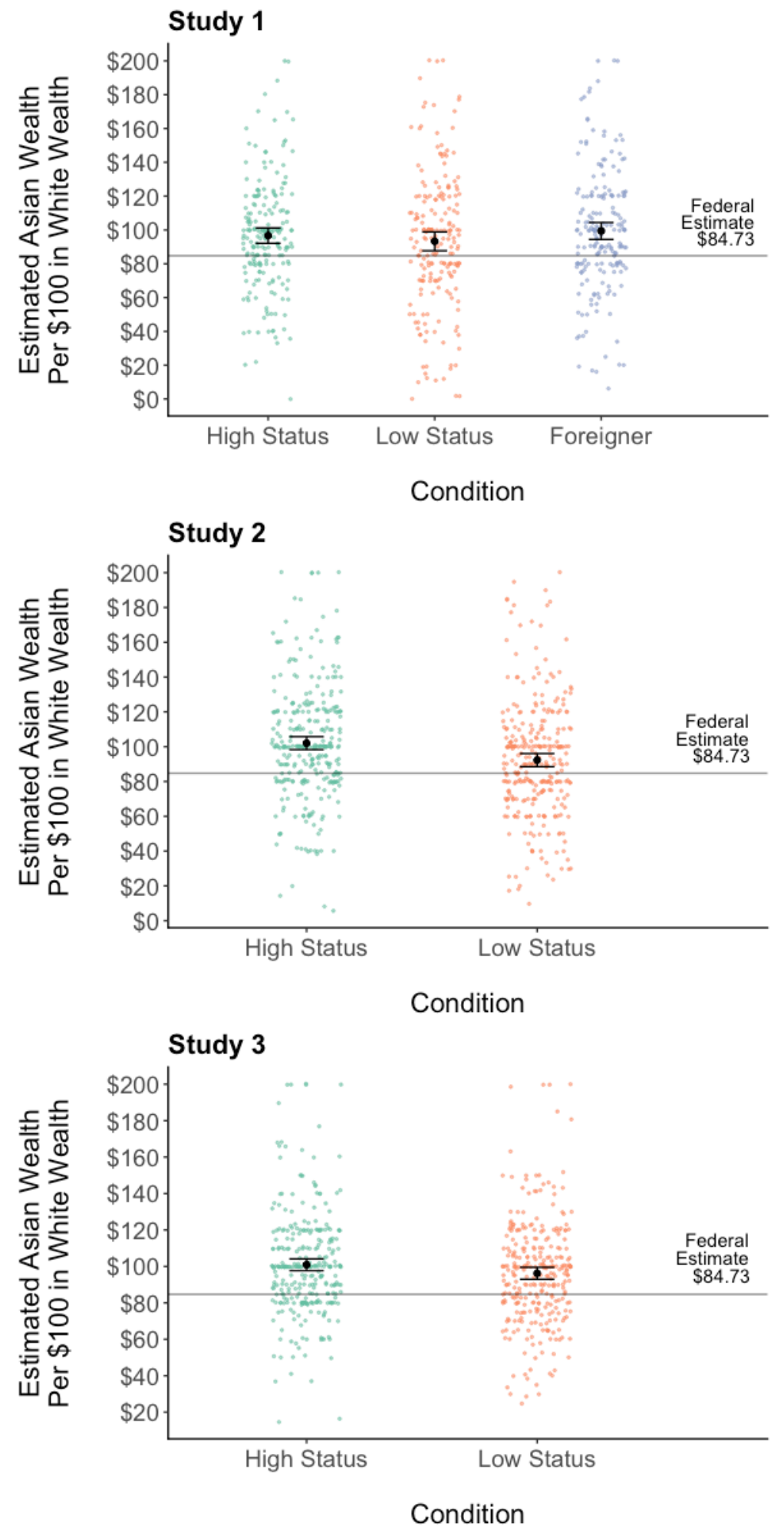

Figure 1. The graphs show overestimates of Asian-White wealth equality across all three studies. Scatterplots represent respondent perceptions of typical family wealth of Asian American relative to White American wealth set to $\$ 100$. The horizontal line represents the federal estimate of the median wealth for Asian Americans when White American wealth is set to $\$ 100$, and was calculated using the 2013 Survey of Income and Program Participation. Error bars indicate $95 \%$ confidence intervals surrounding the mean. 
In Study 3, we manipulated the salience of low-status Asian American exemplars by asking participants to consider perceptions of a variety of Asian-origin subgroups before (lowstatus; $n=305$ ) or after (high-status; $n=307$ ) they estimated general Asian-White wealth equality. Consistent with predictions, an independent samples t-test revealed that participants in the lowstatus (subgroups first) condition made significantly more accurate general Asian-White wealth equality estimates $(M=11.51), C I 95 \%(8.24,14.79)$, than participants in the high-status (general first) condition $(M=16.19), C I 95 \%(12.97,19.41), t(602)=2.00, p=0.046, d=0.16$.

A meta-analysis across all of our studies comparing the low and high-status experimental conditions revealed that participants generated more accurate estimates of Asian-White wealth equality when they were in the low-status rather than high-status condition, $d_{\text {Combined }}=0.19$, $Z_{\text {Combined }}=3.83, p_{\text {Combined }}<0.001$.

\section{Subgroup-Level Estimates of Asian-White Wealth Equality}

At the heart of our rationale for this research is the reality that Asian Americans are best conceived of in disaggregation as unique peoples with their own cultures and immigration histories (Lee \& Zhou, 2015). Related to this central point, another way to test our second hypothesis about status salience is to directly compare general perceptions of Asian-White wealth equality to subgroup-level perceptions when considering Asian Americans as a collection of ten Asian-origin subgroups. Specifically, we expected that estimates of Asian-White wealth equality made while focused on Asian-origin subgroups would be more accurate than generallevel estimates of Asian-White wealth equality.

To test our prediction that estimates based on Asian-origin subgroups would result in greater accuracy, we compared mean subgroup-level perceptions of Asian-White wealth equality (10 items; Study 1: $\alpha=0.97$; Study 2: $\alpha=0.96$; Study 3: $\alpha=0.95$, see Figure 2 ) to general-level perceptions. Consistent with predictions, paired t-test analyses revealed that participants made 
more accurate estimates of Asian-White wealth equality based on mean subgroup-level perceptions of Asian-White wealth in Study 1 (M=-6.11), CI 95\% (-8.94, -3.29), $t(602)=15.85$, $p<0.001, d=1.29$, Study $2(M=-1.19), C I 95 \%(-3.73,1.36), t(606)=14.02, p<0.001, d=1.14$, and Study $3(M=-2.47), C I 95 \%(-4.50,-0.44), t(602)=20.83, p<0.001, d=1.70$, relative to AsianWhite wealth perceptions at the general level.

Across the studies (see Figure 2), a meta-analysis suggests that participants made more accurate estimates of Asian-White wealth equality with mean subgroup-level perceptions than general-level perceptions, $d_{\text {Combined }}=0.46, Z_{\text {Combined }}=13.51, p_{\text {Combined }}<0.001$. Critically, though subgroup-level perceptions reduced overestimates of Asian-White wealth equality, this method of wealth equality assessment actually resulted in inaccuracy in the opposite direction. Mean subgroup-level perceptions elicited inaccurate perceptions of Asian-White wealth equality in Study $1 t(602)=-4.25, p<0.001, d=-0.35$, Study $3 t(602)=-2.39, p=0.017, d=-0.19$, and across the studies in our meta-analysis, $d_{\text {Combined }}=-0.21, Z_{\text {Combined }}=-4.413, p_{\text {Combined }}<0.001$. Only in Study 2 were subgroup-level perceptions consistent with federal data, $t(606)=-0.92, p=0.359, d=-0.07$. However, we do not necessarily interpret these subgroup-level perceptions as overestimates of inequality because the ten subgroups are not equally represented in the Asian American population. For instance, when we computed these composite estimates based on the share of the population per subgroup via the U.S. Census Bureau's 2017 American Community Survey 1Year Estimates (“Asian Alone or in Any Combination By Selected Groups: 2017 American Community Survey 1-Year Estimates,” 2018), the difference between the population-weighted estimate and wealth equality comparator were not different in the combined sample of all the studies, suggesting accuracy when breaking up data into subgroups (see supplement).

An unanticipated result that arose in the subgroup-level perceptions of Asian-White wealth equality is the reliable hierarchy that people perceived in wealth disparities between 
Asian American subgroups and Whites with Japanese and Chinese Americans on top and Cambodian and Hmong Americans at the bottom (see Figure 2). These results are broadly consistent with demographic data on poverty rates in Asian-origin subgroups in America (López et al., 2017).

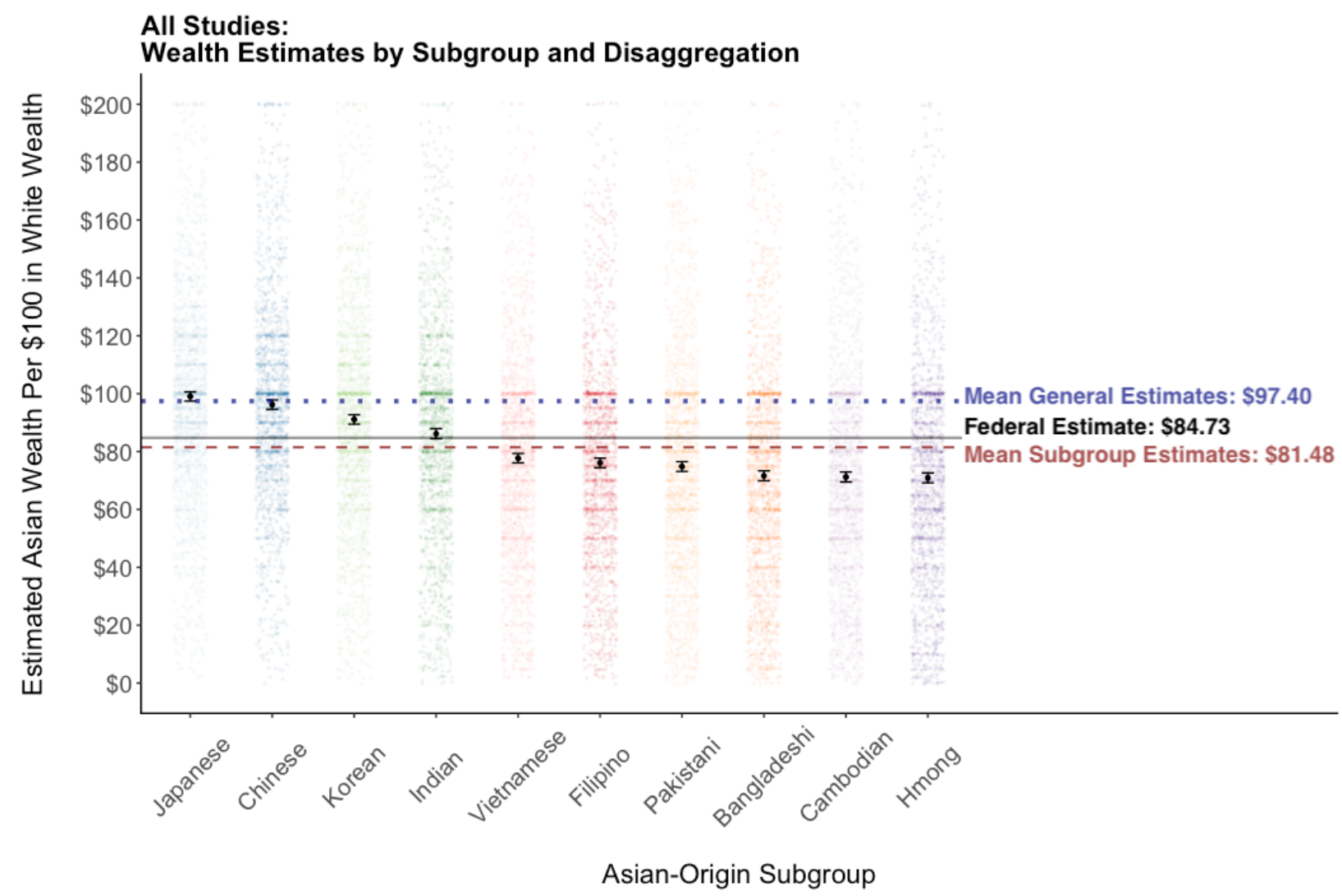

Figure 2. The graph shows estimates of Asian-White wealth equality across ten Asian-origin subgroups, collapsed across all three studies. Individual dots represent individual respondent perceptions of typical family wealth of the Asian subgroups relative to White wealth set to $\$ 100$. The black line represents the federal estimate of the median wealth for Asian Americans when White wealth is set to $\$ 100$, and was calculated using the 2013 Survey of Income and Program Participation. The blue line represents mean estimates of general-level Asian wealth when White wealth is $\$ 100$. The red line represents mean estimates of Asian wealth calculated from the composite of subgroup-level estimates. Error bars indicate $95 \%$ confidence intervals surrounding the mean estimate. 


\section{Preliminary Tests of Mechanism}

We primarily conceived of these studies to examine whether perceptions of the social status of Asian Americans influence overestimates of Asian-White wealth equality, and some mediational analyses are consistent with this prediction. When we examined the influence of our manipulations on the perceived social status of Asian Americans, the overall condition metaanalytic effect was significant in the predicted direction, $d_{\text {Combined }}=-0.19, Z_{\text {Combined }}=-3.701$, $p_{\text {Combined }}<0.001$. We also examined status of Asian Americans as a mediator through an analysis using the PROCESS macro with 5,000 bootstrapped resamples and confidence intervals calculated using the percentile method (Hayes, 2012), and conducted using the combined sample with study as a covariate. This analysis found a significant indirect effect of condition on accuracy in Asian-White wealth estimates through perceived status of Asian Americans, $B=2.26$, $S E=0.64, C I 95 \%(1.08-3.57)$. High-status condition participants' greater relative tendency to overestimate Asian-White wealth equality, $C=6.26, S E=1.62, t(1611)=3.86, p<0.001$, was reduced, $C^{\prime}=4.00, S E=1.51, t(1611)=2.65, p=0.008$, after accounting for participants' selfreported perceptions of Asian Americans' social status (see supplement for full path analysis).

A second potential mechanism at play in our studies involves the expansion of the Asian American overall category to include additional subgroups beyond the high-status groups that are typically activated. Consistent with this second mechanism, in Study 3 we found that the more Asian subgroups participants' tended to include in the overall Asian category, the more accurate their estimates - a finding suggesting that a more diverse rather than prototypical perception of the Asian American category is related to enhanced accuracy in wealth estimates, $R(604)=-.12$, $p=.003$. Thus, subgroup category inclusion is a potential contributor to perceptions of Asian American wealth equality that warrants future research (see supplement).

\section{Discussion}


Asian Americans, a fast-growing racial minority group representing about $5 \%$ of the U.S. population (“U.S. Census Bureau QuickFacts: UNITED STATES,” 2017), are typically perceived as a "model minority" (Zou \& Cheryan, 2017). These prototypical high-status conceptions of Asian Americans motivate the recent litigation against Harvard University, claiming that Asian Americans are underrepresented on college campuses relative to their academic promise as a group.

However, more than a cursory examination of this group reveals a diverse and multifaceted collection of histories - contrary to dominant conceptions of Asian Americans in the media and on many college campuses, some Asian-origin subgroups came to America as refugees and/or live in poverty (López et al., 2017). In this research, we find preliminary evidence that reminding respondents of low- versus high-status Asian American exemplars reduces overestimates of general Asian-White wealth equality. Across three studies, we found a pattern consistent with this prediction. Americans overestimated general Asian-White wealth equality relative to estimates of wealth based on federal data. Moreover, by highlighting lowversus high-status Asian American exemplars, we found general support for the prediction that the relative salience of high-status - relative to low-status - exemplars is causal in this process. To our knowledge, this is the first causal evidence implicating the salience of high-status exemplars in shaping (mis)perceptions of racial wealth equality (e.g., Kraus et al., 2017). However, our conclusions about the data involving ease of exemplar activation is preliminary and needs future research.

A few limitations of the present work bear mentioning. Importantly, the methodology with which respondents estimate wealth inequalities between racial groups is subject to a few qualifications - it is not clear what information participants use to generate these estimates, and the findings depend somewhat on the availability of high-quality economic comparator data on 
wealth inequality (Davidai \& Gilovich, 2018; Swan, Chambers, Heesacker, \& Nero, 2017). We tried to account for both of these limitations by reducing the math participants must do to generate their wealth inequality estimates, by avoiding percentages and instead using equivalent comparisons (Gigerenzer \& Hoffrage, 1995), and by relying on the highest quality comparator data available; namely data from the Survey of Income and Program Participation. Attesting to the quality of these data, when we average across all dates of SIPP data on Asian-White wealth inequality, the comparator estimate becomes $\$ 86.19$ in Asian wealth for every $\$ 100$ in White wealth versus the comparison we used in the studies of $\$ 84.73$. Importantly, all the results reported here remain unchanged with the SIPP aggregate comparator.

In addition, our Study 3 manipulation of status is executed differently than Studies 1 and 2. Whereas the prior two studies highlight group members who are lower versus higher in status among Asian Americans as an aggregate group, Study 3 does this merely by making these subgroups salient prior to or after estimates of aggregate Asian American wealth. We acknowledge that this difference in the type of manipulation suggests a separable set of mechanisms — one of status and one of subgroup salience — in Study 3. However, our mediational analysis did not observe a significant effect of study when entered as a covariate (see supplement). Still, subtle differences in methods highlight two primary mechanisms, perceived Asian American status and subgroup salience, that warrant future research.

\section{Implications}

Ultimately, one implication of this research is that it reveals the tension between conceiving of racial groups in monolithic, category-level terms rather than based on the unique subgroups with distinct histories that make up the larger category (Lee \& Zhou, 2015). As others have argued, we find evidence that when people draw from their perceptions of Asian Americans in aggregate, the over-generalization of the experiences and characteristics of higher-status 
subgroups and exemplars obscure the most vulnerable among Asian American communities. While people can disaggregate, they do not when perceiving Asian Americans at the larger overall category level, and this, in part, reflects a focus on higher-status Asian-origin subgroups (e.g., Chinese Americans) when estimating Asian American wealth equality relative to Whites. Conceiving of Asian Americans as high-status, for instance, may divert social safety net programs away from communities living in poverty or close off affirmative action admissions policies that increase the representation of members of Asian subgroups that-like Black and Latinx Americans_-remain underrepresented at universities (Lee \& Bean, 2010).

Overall, this research fits into a growing body of work suggesting — with a few exceptions (Chambers, Swan, \& Heesacker, 2015; Martin, Nezlek, \& Voracek, 2014) — that Americans tend to be overly optimistic about economic equality in society in general and in particular, with respect to the way resources are shared between racial groups (Kraus et al., 2017). The current work suggests that this pattern of overly-optimistic belief, which is not born out in data, extends beyond Black Americans and even applies to a relatively high-status racial minority group. That is, although smaller in magnitude than the misperception of Black-White wealth equality, the perception of racial wealth equality between Asian and White Americans outstrips reality. Given that solidarity between racial groups is engendered by the perception of shared experiences with discrimination (Cortland et al., 2017; Craig \& Richeson, 2012), a more nuanced understanding of wealth inequality in Asian American communities may be essential for interracial coalition building. 


\section{References}

Adler, N. E., Epel, E. S., Castellazzo, G., \& Ickovics, J. R. (2000). Relationship of Subjective and Objective Social Status With Psychological and Physiological Functioning: Preliminary Data in Healthy White Women. Health Psychology, 19(6), 586-592. https://doi.org/10.1037/0278-6133.19.6.586

Asian Alone or in Any Combination By Selected Groups: 2017 American Community Survey 1Year Estimates. (2018). Retrieved April 28, 2019, from United States Census Bureau website: https://factfinder.census.gov/faces/tableservices/jsf/pages/productview.xhtml?pid=ACS_17 _1YR_B02018\&prodType=table

Bai, H. (2018). Evidence that A Large Amount of Low Quality Responses on MTurk Can Be Detected with Repeated GPS Coordinates. Retrieved November 26, 2018, from https://www.maxhuibai.com/blog/evidence-that-responses-from-repeating-gps-are-random

Brown-Iannuzzi, J. L., Dotsch, R., Cooley, E., \& Payne, B. K. (2017). The Relationship Between Mental Representations of Welfare Recipients and Attitudes Toward Welfare.

Psychological Science, 28(1), 92-103. https://doi.org/10.1177/0956797616674999

Chambers, J. R., Swan, L. K., \& Heesacker, M. (2015). Perceptions of U.S. Social Mobility Are Divided (and Distorted) Along Ideological Lines. Psychological Science, 26(4), 413-423. https://doi.org/10.1177/0956797614566657

Cortland, C. I., Craig, M. A., Shapiro, J. R., Richeson, J. A., Neel, R., \& Goldstein, N. J. (2017). Solidarity through shared disadvantage: Highlighting shared experiences of discrimination improves relations between stigmatized groups. Journal of Personality and Social Psychology, 113(4), 547-567. https://doi.org/10.1037/pspi0000100

Craig, M. A., \& Richeson, J. A. (2012). Coalition or derogation? How perceived discrimination 
influences intraminority intergroup relations. Journal of Personality and Social Psychology, 102(4), 759-777. https://doi.org/10.1037/a0026481

Davidai, S., \& Gilovich, T. (2018). How should we think about Americans’ beliefs about economic mobility? Judgment \& Decision Making, 13(3), 297-304. Retrieved from https://search.ebscohost.com/login.aspx?direct=true\&db=a9h\&AN=130110898\&site=ehostlive $\&$ scope $=$ site

Eibach, R. P., \& Ehrlinger, J. (2006). "Keep Your Eyes on the Prize”: Reference Points and Racial Differences in Assessing Progress Toward Equality. Personality and Social Psychology Bulletin, 32(1), 66-77. https://doi.org/10.1177/0146167205279585

Fiske, S. T., Cuddy, A. J. C., Glick, P., \& Xu, J. (2002). A model of (often mixed) stereotype content: Competence and warmth respectively follow from perceived status and competition. Journal of Personality and Social Psychology, 82(6), 878-902. https://doi.org/10.4324/9781315187280

Gigerenzer, G., \& Hoffrage, U. (1995). How to improve Bayesian reasoning without instruction: Frequency formats. Psychological Review, 102(4), 684-704. https://doi.org/10.1037/0033295X.102.4.684

Goh, J. X., Hall, J. A., \& Rosenthal, R. (2016). Mini Meta-Analysis of Your Own Studies: Some Arguments on Why and a Primer on How. Social and Personality Psychology Compass, 10, 535-549. https://doi.org/10.1111/spc3.12267

Hamilton, D., Darity, W., Price, A. E., Sridharan, V., \& Tippett, R. (2015). Umbrellas Don't Make it Rain: Why Studying and Working Hard Isn't Enough for Black Americans. Retrieved from www.racialwealthgap.org.

Hayes, A. F. (2012). PROCESS: A versatile computational tool for observed variable mediation, moderation, and conditional process modeling. White Paper Retrieved from 
http://www.afhayes.com/ public/process2012.pdf process:, 1-39. https://doi.org/978-160918-230-4

Kiatpongsan, S., \& Norton, M. I. (2014). How Much (More) Should CEOs Make? A Universal Desire for More Equal Pay. Perspectives on Psychological Science, 9(6), 587-593. https://doi.org/10.1177/1745691614549773

Kim, C. J. (1999). The Racial Triangulation of Asian Americans. Politics \& Society, 27(1), 105138. https://doi.org/10.1177/0032329299027001005

Kochhar, R., \& Cillufo, A. (2018). Income Inequality in the U.S. is Rising Most Rapidly Among Asians. 1-23. https://doi.org/202.419.4372

Kraus, M. W., Rucker, J. M., \& Richeson, J. A. (2017). Americans misperceive racial economic equality. Proceedings of the National Academy of Sciences, 114(39), 10324-10331. https://doi.org/10.1073/PNAS.1707719114

Lee, J., \& Bean, F. D. (2010). The Diversity Paradox: Immigration and the Color Line in Twenty-First Century America. New York: Russell Sage Foundation.

Lee, J., \& Zhou, M. (2015). The Asian American Achievement Paradox. New York: Russell Sage Foundation.

Lei, R. F., \& Bodenhausen, G. V. (2017). Racial Assumptions Color the Mental Representation of Social Class. Frontiers in Psychology, 8, 519. https://doi.org/10.3389/fpsyg.2017.00519

Lipkus, I. (1991). The construction and preliminary validation of a global belief in a just world scale and the exploratory analysis of the multidimensional belief in a just world scale. Personality and Individual Differences, 12(11), 1171-1178. https://doi.org/10.1016/01918869(91)90081-L

López, G., Ruiz, N. G., \& Patten, E. (2017). Key facts about Asian Americans, a diverse and growing population. Pew Research Center. Retrieved from 
http://www.pewresearch.org/fact-tank/2017/09/08/key-facts-about-asian-americans/

Martin, C. C., Nezlek, J. B., \& Voracek, M. (2014). The White Ceiling Heuristic and the Underestimation of Asian-American Income. PLoS ONE, 9(9).

https://doi.org/10.1371/journal.pone.0108732

Montgomery, J. M., Nyhan, B., \& Torres, M. (2018). How Conditioning on Posttreatment Variables Can Ruin Your Experiment and What to Do about It. American Journal of Political Science, 62(3), 760-775. https://doi.org/10.1111/ajps.12357

Norton, M. I., \& Ariely, D. (2011). Building a Better America-One Wealth Quintile at a Time. Perspectives on Psychological Science, 6(1), 9-12.

https://doi.org/10.1177/1745691610393524

Ong, A. D., Burrow, A. L., Fuller-Rowell, T. E., Ja, N. M., \& Sue, D. W. (2013). Racial microaggressions and daily well-being among Asian Americans. Journal of Counseling Psychology, 60(2), 188.

Park, J. Z. (2008). Second-Generation Asian American Pan-Ethnic Identity: Pluralized Meanings of a Racial Label. Sociological Perspectives, 51(3), 541-561. https://doi.org/10.1525/sop.2008.51.3.541

Pratto, F., Sidanius, J., Stallworth, L. M., \& Malle, B. F. (1994). Social Dominance Orientation: A Personality Variable Predicting Social and Political Attitudes. Journal of Personality and Social Psychology, 67(4), 741-763. https://doi.org/10.1037/0022-3514.67.4.741

Ramakrishnan, K., Lee, J., Lee, T., \& Wong, J. (2017). National Asian American Survey (NAAS) 2016 Pre-Election Survey. Riverside, CA.

Richard, F. D., Bond, C. F., \& Stokes-Zoota, J. J. (2003). One Hundred Years of Social Psychology Quantitatively Described Article in Review of General Psychology. Review of General Psychology, 7(4), 331-363. https://doi.org/10.1037/1089-2680.7.4.331 
Spickard, P. (1999). Mixed Blood: Intermarriage and Ethnic Identity in Twentieth-century America. The University of Wisconsin Press.

Sue, D. W., Bucceri, J., Lin, A. I., Nadal, K. L., \& Torino, G. C. (2007). Racial microaggressions and the Asian American experience. Cultural Diversity and Ethnic Minority Psychology, 13(1), 72-81. https://doi.org/10.1037/1099-9809.13.1.72

Swan, L. K., Chambers, J. R., Heesacker, M., \& Nero, S. S. (2017). How should we measure American's perceptions of socio-economic mobility? Judgment and Decision Making, 12(5), 507-515. Retrieved from http://dcccd.idm.oclc.org/login?url=http://search.ebscohost.com/login.aspx?direct=true\&db $=$ a 9 h $\& A N=125952585 \&$ site $=$ ehost-live

U.S. Census Bureau QuickFacts: UNITED STATES. (2017). Retrieved November 26, 2018, from U.S. Department of Commerce website: https://www.census.gov/quickfacts/fact/table/US/PST045217\#PST045217

Wealth, Asset Ownership, \& Debt of Households Detailed Tables: 2013. (2013). Retrieved April 28, 2019, from United States Census Bureau website: https://www.census.gov/data/tables/2013/demo/wealth/wealth-asset-ownership.html

Wilkins, C. L., Hirsch, A. A., Kaiser, C. R., \& Inkles, M. P. (2017). The threat of racial progress and the self-protective nature of perceiving anti-White bias. Group Processes \& Intergroup Relations, 20(6), 801-812. https://doi.org/10.1177/1368430216631030

Willer, R., Feinberg, M., \& Wetts, R. (2016). Threats to Racial Status Promote Tea Party Support among White Americans. https://doi.org/10.2139/ssrn.2770186

Xu, J., \& Lee, J. C. (2013). The Marginalized “Model” Minority: An Empirical Examination of the Racial Triangulation of Asian Americans. Social Forces, 91(4), 1363-1397. https://doi.org/10.1093/sf/sot049 
Zong, J., \& Batalova, J. (2016). Asian Immigrants in the United States. Retrieved from https://www.migrationpolicy.org/article/asian-immigrants-united-states

Zou, L. X., \& Cheryan, S. (2017). Two Axes of Subordination: A New Model of Racial Position. Journal of Personality and Social Psychology, 112(5), 696-717.

https://doi.org/10.1037/pspa0000080 


\section{Supplementary Materials}

\section{Preregistered Analyses Not Appearing in the Main Text}

In Study 3, we asked participants at the end of the survey to indicate whether or not they completed the survey carefully without any consequences toward their compensation. Of the sample, 602 participants (98\%) indicated that they completed the survey carefully, and the number of participants who completed the survey carefully did not differ by condition, $t(605)=$ $-.45, p=.651$. All of our analyses remain the same with or without participants who completed the survey carefully included.

Based on our preregistration in Study 3, we also explored the possible interaction between condition and estimate type (general vs. subgroup-level) by conducting a two (condition) by two (estimate type) mixed ANOVA with estimate type as the within-subjects factor. Consistent with predictions, there was a significant main effect of estimate type such that mean subgroup-level Asian-White wealth equality estimates $(M=-2.47, C I 95 \%(-4.50,-.44))$ were more accurate than general Asian-White wealth equality estimates $(F(1,601)=439.98, p<$ 0.001). There was also significant main effect of the our manipulation such that participants made significantly more accurate general and subgroup-level Asian-White wealth gap estimates in the low-status $(M=2.26, C I 95 \%(-.58,5.11))$ compared to the high-status condition $(M=$ 9.14, $C I 95 \%(6.31,11.98)), F(1,602)=11.317, p=0.001$. There was a significant interaction between condition and estimate type, $F(1,601)=8.73, p=0.003$. Post-hoc pairwise comparisons revealed that our manipulation had a stronger effect for subgroup-level estimates $(p<0.001)$ than for general estimates $(p=0.51)$.

\section{Aggregated Subgroup Perceptions and Wealth Equality Estimates}

While aggregating across subgroup-level estimates seemed to generate inaccuracy of Asian-White wealth equality, we are cautious about interpreting these Asian origin subgroup 
composites as undrestimates of wealth equality because the ten subgroups are not equally represented in the Asian American population. For instance, when we computed these estimates based on the share of each subgroup's population via census data, the population-weighted estimate and the wealth equality comparator were not different, suggesting accuracy when breaking up data into subgroups.

We used data from the U.S. Census Bureau's 2017 American Community Survey 1-Year Estimates (“Asian Alone or in Any Combination By Selected Groups: 2017 American Community Survey 1-Year Estimates," 2018) to obtain the population of each of the ten Asian origin subgroups (see Table S1). The ACS is an ongoing nation-wide survey that provides yearly social, economic, housing, and demographic statistics updates to the decennial census. In total, the ten subgroups have a population of 20,295,947, which accounts for account for $90.57 \%$ of all Asian Americans. Each subgroup estimate was weighted by the proportion of the subgroup's population over the total population of the ten subgroups: Chinese (25\%), Indian (22\%), Filipino (20\%), Vietnamese (10\%), Korean (9\%), Japanese (7\%), Pakistani (3\%), Cambodian (1.6\%), Hmong (1.5\%), Bangladeshi (0.9\%). Weighted subgroup-level estimate accuracy $(M=-1.96), C I$ $95 \%(-4.73,0.81)$ was not significantly different from zero, $t(602)=-1.39, p=0.165$, indicating that after accounting for the relative sizes of Asian subgroups that differ in wealth, subgrouplevel perceptions of Asian-White wealth equality are accurate. 
Table S1. Population and Weighting of Asian Origin Subgroups

\begin{tabular}{lcc}
\hline Subgroup & Population & Weight \\
\hline Chinese & $5,025,817$ & $25 \%$ \\
Indian & $4,402,362$ & $22 \%$ \\
Filipino & $4,037,564$ & $20 \%$ \\
Vietnamese & $2,104,217$ & $10 \%$ \\
Korean & $1,887,914$ & $9 \%$ \\
Japanese & $1,466,514$ & $7 \%$ \\
Pakistani & 544,640 & $3 \%$ \\
Cambodian & 331,733 & $1.6 \%$ \\
Hmong & 309,564 & $1.5 \%$ \\
Bangladeshi & 185,622 & $0.9 \%$ \\
\hline
\end{tabular}

Note. Data is from the U.S. Census Bureau's American Community Survey 2017 Estimates. Each subgroup is weighted by the proportion of the subgroup's population over the total population of the ten subgroups $(20,295,947$, which accounts for account for $90.57 \%$ of all Asian Americans).

Table S2. Psychological Correlates of Asian-White Wealth Estimates

\begin{tabular}{|c|c|c|c|c|c|c|c|c|}
\hline Variable & $\begin{array}{c}\text { Asian } \\
\text { American } \\
\text { status } \\
\end{array}$ & Familiarity & Conservative & $\begin{array}{c}\text { Just world } \\
\text { beliefs }\end{array}$ & $\begin{array}{c}\text { Social } \\
\text { dominance }\end{array}$ & $\begin{array}{l}\text { Subgroup } \\
\text { inclusion }\end{array}$ & Race & Gender \\
\hline \multicolumn{9}{|l|}{ Study 1} \\
\hline Mean(SD) & $6.47(1.79)$ & $2.65(0.94)$ & $3.87(1.83)$ & $3.66(1.20)$ & - & - & - & - \\
\hline $\mathrm{r}$ & $0.28^{*}$ & $0.24 *$ & $0.22 *$ & $0.19^{*}$ & 一 & - & 0.01 & $0.12 *$ \\
\hline \multicolumn{9}{|l|}{ Study 2} \\
\hline Mean(SD) & $6.35(1.72)$ & $2.58(0.88)$ & $3.78(1.74)$ & $3.55(1.09)$ & $2.77(1.35)$ & - & - & - \\
\hline $\mathrm{r}$ & $0.44 *$ & $0.32 *$ & $0.32 *$ & $0.27 *$ & $0.23 *$ & - & 0.04 & $0.15^{*}$ \\
\hline \multicolumn{9}{|l|}{ Study 3} \\
\hline Mean(SD) & $6.81(1.56)$ & - & $3.03(1.58)$ & - & - & $5.82(2.55)$ & - & - \\
\hline $\mathrm{r}$ & $0.36^{*}$ & 一 & $0.21 *$ & - & - & $-0.12 *$ & 0.06 & $0.11 *$ \\
\hline \multicolumn{9}{|c|}{ Meta-Analysis } \\
\hline$r_{\text {Combined }}$ & $0.36^{*}$ & $0.28^{*}$ & $0.31 *$ & $0.23 *$ & - & - & 0.04 & $0.13 *$ \\
\hline$Z_{\text {Combined }}$ & $16.05^{*}$ & $10.08^{*}$ & $6.20 *$ & $8.15^{*}$ & - & - & 1.56 & $5.41 *$ \\
\hline
\end{tabular}

Note. The asterisk after a correlation coefficient indicates that $p<0.05$. Asian American status, perceived social status of Asian Americans; Familiarity, familiarity with Asian origin subgroups; Conservative, political conservatism; Just world beliefs, belief in a just world; Social dominance, social dominance orientation; Subgroup inclusion, inclusion of Asian origin subgroups; Race, race coded as -1 for non-white and 1 for white; Gender, gender coded as -1 for female and 1 for male. Blank cells indicate that the construct was not measured in during that particular study or that descriptive statistics were not calculated for dummy-coded variables. 


\section{Potential Mechanisms Leading to Asian-White Wealth Equality Estimate Inaccuracy}

We tested some potential mechanisms that likely underlie our effects and lead people to overestimate Asian-White wealth equality. First, we examined the extent to which the perceived social status of Asian Americans, familiarity with Asian origin subgroups, political ideology, belief in a just world, social dominance orientation, inclusion of Asian origin subgroups, race (coded as -1 for non-White and 1 for White), and gender (coded as -1 for female and 1 for male) were correlated with general estimates of Asian-White wealth equality. Table S2 presents these correlations. Positive correlations emerged between overestimates of Asian-White wealth equality and ratings of Asian Americans as high in social status, a pattern that aligns with our central predictions.

Importantly, no condition differences emerged on these variables save for perceived Asian American status (see Table S3), which was not significantly different in Study $1(F(2,600)$ $=0.093, p=0.911)$ or Study $3(t(602)=-1.24, p=0.216)$ but was significant in Study 2 , in which the perceived social status of Asian Americans was significantly shifted by the manipulation such that the high-status condition increased perceptions of the status of Asian Americans relative to the low-status condition, $t(605)=-4.62, p<0.001$. The overall condition meta-analytic effect was positive and significant, $d_{\text {Combined }}=-0.19, Z_{\text {Combined }}=-3.701, p_{\text {Combined }}<$ 0.001 . 
Table S3. Psychological Correlates of Asian-White Wealth Estimates by Condition

\begin{tabular}{|c|c|c|c|c|c|c|}
\hline Variable & $\begin{array}{c}\text { Asian } \\
\text { American } \\
\text { status } \\
\end{array}$ & Familiarity & Conservative & $\begin{array}{c}\text { Just world } \\
\text { beliefs }\end{array}$ & $\begin{array}{c}\text { Social } \\
\text { dominance }\end{array}$ & $\begin{array}{c}\text { Subgroup } \\
\text { inclusion }\end{array}$ \\
\hline \multicolumn{7}{|l|}{ Study 1} \\
\hline Low-Status & $6.43(1.72)$ & $2.65(0.97)$ & $3.88(1.86)$ & $3.70(1.22)$ & - & - \\
\hline High-Status & $6.49(1.96)$ & $2.60(0.90)$ & $3.89(1.81)$ & $3.60(1.21)$ & - & - \\
\hline Foreigner & $6.50(1.69)$ & $2.71(0.94)$ & $3.83(1.82)$ & $3.67(1.16)$ & - & - \\
\hline F-value & 0.09 & 0.66 & 0.05 & 0.34 & - & - \\
\hline \multicolumn{7}{|l|}{ Study 2} \\
\hline Low-Status & $6.03(1.74)$ & $2.55(0.87)$ & $3.89(1.72)$ & $3.59(1.09)$ & $2.77(1.33)$ & - \\
\hline High-Status & $6.67(1.65)$ & $2.60(0.88)$ & $3.68(1.76)$ & $3.51(1.10)$ & $2.76(1.37)$ & - \\
\hline t-value & $4.62 *$ & 0.73 & -1.44 & -0.93 & -0.08 & - \\
\hline \multicolumn{7}{|l|}{ Study 3} \\
\hline Low-Status & $6.73(1.61)$ & - & $3.08(1.60)$ & - & - & $5.66(2.46)$ \\
\hline High-Status & $6.88(1.50)$ & - & $2.98(1.57)$ & - & - & $5.97(2.63)$ \\
\hline t-value & 1.24 & - & -0.77 & - & - & -1.54 \\
\hline \multicolumn{7}{|l|}{ Meta-Analysis } \\
\hline$d_{\text {Combined }}$ & $-0.185^{*}$ & -0.014 & 0.067 & 0.036 & - & - \\
\hline$Z_{\text {Combined }}$ & $-3.704 *$ & -0.226 & 1.341 & 0.568 & - & - \\
\hline
\end{tabular}

Note. The asterisk after an F-value or t-value indicates that $p<0.05$. Asian American status, perceived social status of Asian Americans; Familiarity, familiarity with Asian origin subgroups; Conservative, political conservatism; Just world beliefs, belief in a just world; Social dominance, social dominance orientation; Subgroup inclusion, inclusion of Asian origin subgroups. Blank cells indicate that the construct was not measured in during that particular study.

Other significant correlates of overestimates of Asian-White wealth equality included political conservatism and belief in a just world, a pattern consistent with prior research estimating racial wealth equality between Black and White Americans (Kraus et al., 2017). As well, in Study 3, the more Asian subgroups participants' tended to include in the overall Asian category the more accurate their estimates — a finding suggesting that a more diverse rather than prototypical perception of the Asian American category is related to enhanced accuracy in wealth estimates. Thus, subgroup category inclusion is a process in perceptions of Asian American wealth that warrants future research.

Being higher in social dominance orientation and being male were associated with greater overestimates of Asian-White wealth equality. Being more familiar with Asian American subgroups was positively associated with overestimates of Asian-White wealth equality - this association is counterintuitive because we expected more familiarity with Asian origin subgroups 
to decrease the salience of model minority exemplars. We do not interpret this association further given that it does not emerge in our regression analysis as a predictor of Asian-White wealth equality.

One possibility arising from our general status salience hypothesis is that individual differences in perception of Asian American group status would predict overestimates of AsianWhite wealth equality after accounting for plausible psychological correlates of participant wealth estimates. We explored this possibility using a linear regression analysis predicting estimates of general Asian-White wealth equality with perceived status of Asian Americans and all relevant correlates presented in Table S2. For Study 1, perceived Asian American status, familiarity with Asian subgroups, political conservatism, belief in a just world, race, and gender, and condition (with the low-status condition as the reference group) were entered into the regression analysis to predict overestimates of Asian-White wealth equality. The model explained a significant amount of variance in overestimates of wealth equality, $R^{2}=16 \%, F(8$, $594)=14.31, p<0.001$. Asian American status $(\beta=0.24, t(594)=6.36, p<0.001)$, familiarity with Asian subgroups $(\beta=0.17, t(594)=4.13, p<0.001)$, and political conservatism $(\beta=0.15$, $t(594)=3.38, p=0.001)$ were significant predictors of overestimates of Asian-White wealth equality. No other variables emerged as significant predictors in the model.

For Study 2, perceived Asian American status, familiarity with Asian subgroups, political conservatism, belief in a just world, social dominance orientation, race, gender, and condition (with the low-status condition as the reference group) were entered into the regression model, which explained a significant amount of variance in overestimates of Asian-White wealth equality, $R^{2}=32 \%, F(8,598)=34.68, p<0.001$. Asian American status $(\beta=0.34, t(598)=9.40$, $p<0.001)$, familiarity with Asian subgroups $(\beta=0.22, t(598)=5.94, p<0.001)$, political conservatism $(\beta=0.19, t(598)=4.43, p<0.001)$, race $(\beta=0.11, t(598)=3.15, p=0.002)$, and 
condition $(\beta=0.09, t(598)=2.62, p=0.009)$ were significant predictors of overestimates of Asian-White wealth equality. No other predictors emerged in the model.

For Study 3, perceived Asian American status, political conservatism, inclusion of Asian subgroups, race, gender, and condition (with the low-status condition as the reference group) were entered into the regression model, which explained a significant amount of variance in overestimates of Asian-White wealth equality, $R^{2}=20 \%, F(6,596)=24.28, p<0.001$. Asian American status $(\beta=0.36, t(596)=9.70, p<0.001)$, political conservatism $(\beta=0.16, t(596)=$ $4.26, p<0.001)$, race $(\beta=0.12, t(596)=3.26, p=0.001)$, gender $(\beta=0.09, t(596)=2.38, p=$ $0.017)$, and condition $(\beta=0.08, t(596)=2.22, p=0.027)$ were significant predictors of overestimates of Asian-White wealth equality. No other predictors emerged in the model.

Across all three studies, perceptions of Asian American status remained a significant predictor of overestimates of Asian-White wealth equality even after controlling for our manipulation and all other psychological correlates, which provides further support for our status salience hypothesis. As well, both political conservatism and race emerged as predictors of overestimates of Asian-White wealth equality, consistent with prior research estimating racial wealth equality between Black and White Americans (Kraus et al., 2017).

Furthermore, a mediation analyses across all studies indicated that perceived status of Asian Americans statistically accounted for the observed tendency for participants in the lowstatus conditions to make more accurate estimates of Asian-White wealth equality relative to participants in the high-status conditions. The coefficients and test statistics for the analysis accounting for differences in accuracy in Asian-White wealth estimates between participants in the low- versus high-status conditions are reported in Table S4. The analysis controlled for study, which had no effect as a control variable, and included a bootstrapping analysis with 2,000 bootstrapped samples. In all studies, participants in the low-status condition perceived Asian 
Americans to have lower social status than did participants in the high-status condition.

Perceived status was, in turn, predictive of accuracy in Asian-White wealth estimates. Moreover, accounting for this mediator reduced the significant total effect of condition on accuracy in Asian-White wealth estimates (i.e., the C versus C' paths).

The analysis revealed a significant indirect effect of condition on accuracy in AsianWhite wealth estimates through perceived status of Asian Americans $(B=2.26, S E=0.64, C I$ $95 \%(1.08-3.57))$. See the full path analysis in Table S4.

Table S4. Coefficients from the analysis explaining differences between participants in the low-status and high-status conditions on accuracy in Asian-White wealth estimates using perceived status of Asian Americans as a mediator while controlling for study

\begin{tabular}{lcccc}
\hline Variable & Coefficient & SE & t-value & $\boldsymbol{p}$ value \\
\hline Condition to Asian American status (a path) & 0.31 & 0.08 & 3.72 & $<0.001$ \\
Asian American status to accuracy (b path) & 7.21 & 0.44 & 16.21 & $<0.001$ \\
Total effect (c path) & 6.26 & 1.62 & 3.86 & $<0.001$ \\
Direct effect (c' path) & 4.00 & 1.51 & 2.65 & 0.008 \\
Partial effect of study (control variable) & 0.37 & 0.97 & 0.38 & 0.706 \\
\hline
\end{tabular}

Table S5. Coefficients from the moderated-mediation analysis explaining differences between participants in the low-status and high-status conditions on accuracy in Asian-White wealth estimates using perceived status of Asian Americans as a mediator and study method of status manipulation as a moderator.

\begin{tabular}{lcccc}
\hline Variable & Coefficient & SE & t-value & $\boldsymbol{p}$ value \\
\hline Condition to Asian American status (a path) & 0.41 & 0.11 & 3.84 & $<0.001$ \\
Asian American status to accuracy (b path) & 7.23 & 0.55 & 16.32 & $<0.001$ \\
Direct effect (c' path) & 4.00 & 1.50 & 2.65 & 0.008 \\
Conditional effect on M (Studies 1 and 2) & 0.41 & 0.11 & 3.84 & $<.001$ \\
Conditional effect on M (Study 3) & 0.16 & 0.14 & 1.14 & 0.253 \\
Interaction effect of study method & -1.81 & 1.23 & -1.44 & 0.150 \\
\hline
\end{tabular}

Because Study 3 relied on a markedly different methodology than the first two studies for its manipulation of Asian American group status, it is possible that the mediation analysis is moderated by type of study methodology. To that end, we also conducted a moderated-mediation 
analysis using Model 7 in PROCESS with the same 5,000 bootstrapped resamples with percentile calculated confidence intervals (Hayes, 2012). In that analysis, even though the effect of condition on Asian American status was significant in the first two studies and nonsignificant in the third study, the size of these two conditional effects did not differ by from each other (see Table S5).

\section{Race and Estimates of Asian-White Wealth Equality}

When examining White versus nonwhite respondents, race was not associated with greater overestimates of Asian-White wealth equality, a pattern that is inconsistent with prior research, although that research examined race associations with Black-White wealth equality perceptions (Kraus et al., 2017). When we examined Black and Latinx participants relative to other racial groups, Black and Latinx participants did not make significantly different general Asian-White wealth equality estimates compared to other racial groups in Study $1(t(601)=-$ $0.25, p=0.801)$, Study $2(t(605)=1.94, p=0.053)$, or Study $3(t(602)=-0.42, p=0.676)$.

We also examined whether wealth equality estimates were more accurate among Asian American participants compared to non-Asian American participants. In Study 1, estimates among Asian American $(M=7.25, C I 95 \%(-3.42,17.92))$ and non-Asian American participants $(M=12.10, C I 95 \%(9.07,15.13))$ were not significantly different, $t(601)=0.89, p=0.376$. In Study 2, estimates among Asian American $(M=7.95, C I$ 95\%(-4.17, 20.08)) and non-Asian American participants $(M=12.77, C I 95 \%(10.02,15.51))$ were also not significantly different, $t(605)=0.89, p=0.376$. In Study 3 , estimates among Asian American $(M=7.08, C I 95 \%(0.43$, 13.72) $)$ and non-Asian American participants $(M=14.56, C I 95 \%(12.13,17.00))$ were also not significantly different, $t(602)=1.88, p=0.061$. While there was no difference within each individual study, a meta-analysis across all of our studies revealed that Asian American participants made significantly more accurate estimates of Asian-White wealth equality than did 
non-Asian American participants, $d_{\text {Combined }}=1.85, Z_{\text {Combined }}=2.14, p_{\text {Combined }}=0.032$.

\section{Differential Wealth Equality Estimates by Manipulation Check Failure Rate}

Only in Study 1 did participants differentially fail the manipulation check by condition, $F(2,600)=4.80, p=0.009$. The high-status condition $(M=0.12, C I 95 \%(0.07,0.16))$ had a lower failure rate than both the low-status condition $(M=0.24, C I 95 \%(0.18,0.30), t(600)=$ $3.05, p=0.002)$ and the foreigner condition $(M=0.20, C I 95 \%(0.14,0.25), t(600)=1.99, p=$ 0.047).

In Study 1, participants who failed the manipulation check were significantly less accurate in their wealth equality estimates across all conditions and within the low-status and foreigner conditions, but not in the high-status condition. Across all conditions, participants who failed the manipulation check made significantly less accurate wealth equality estimates $(M=$ $27.50, C I 95 \%(19.30,35.71))$ than participants who passed the manipulation check $(M=8.15$, $C I 95 \%(5.18,11.12)), t(140.80)=4.39, p<0.001, d=.95$. Within the low-status condition, participants who failed the manipulation check made significantly less accurate wealth equality estimates $(M=27.79, C I 95 \%(14.54,41.04))$ than participants who passed the manipulation $\operatorname{check}(M=2.61, C I 95 \%(-3.20,8.41)), t(66.78)=3.49, p=0.001, d=1.01$. Within the foreigner condition, participants who failed the manipulation check made significantly less accurate wealth equality estimates $(M=27.71, C I 95 \%(14.06,41.35))$ than participants who passed the manipulation check $(M=11.51, C I 95 \%(6.30,16.72)), t(50.25)=2.24, p=0.030, d=$ 0.79. Only within the high-status condition, participants who failed the manipulation check did not make significantly different wealth equality estimates $(M=26.60, C I 95 \%(8.07,45.14))$ compared to participants who passed the manipulation check $(M=9.96, C I 95 \%(5.45,14.48))$, $t(26.09)=1.80, p=0.084$ 